\title{
Sclerotherapy-associated esophageal hematoma in a patient with myelofibrosis and portal hyper- tension
}

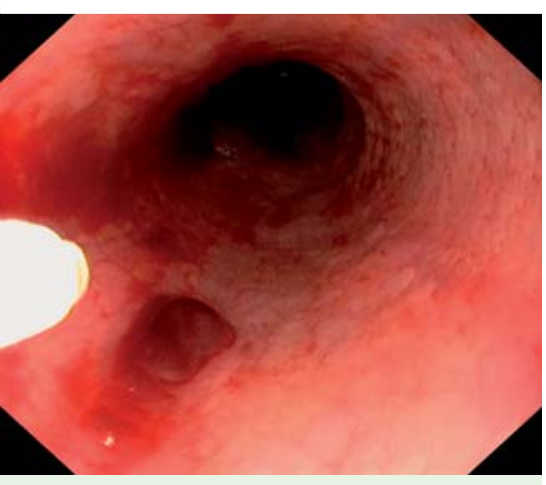

Fig. 1 After an endoscopic ligation procedure for esophageal varices, small bluish lesions are observed during withdrawal of the endoscope.

A 71-year-old woman with primary myelofibrosis and esophageal varices was admitted for her first rubber band ligation procedure (platelet count, 58000/ $\mathrm{mm}^{3}$; partial thromboplastin time, $33.4 \mathrm{sec}-$ onds; international normalized ratio, 1.28). At endoscopy, the esophageal mucosa was extremely fragile and difficult to aspirate into the ligation device. Three of the six rubber bands placed at the gastroesophageal junction slipped off, leaving oozing blood. This was treated by injecting $3.5 \mathrm{~mL}$ of polidocanol (Aethoxysklerol; Base Pharma, Gordon, NSW, Australia). During withdrawal of the endoscope, several areas with bluish bullous lesions (each $<1 \mathrm{~cm}$ in diameter) were observed in the upper two-thirds of the esophagus ( $\bullet$ Fig. 1). One of these lesions, which showed slight oozing of blood, was injected with $1 \mathrm{~mL}$ of polidocanol.
Hematemesis developed 4 hours later, with a drop in the hemoglobin concentration of $0.8 \mathrm{~g} / \mathrm{dL}$ to $10.2 \mathrm{~g} / \mathrm{dL}$. At secondlook endoscopy, the submucosal bullae involved up to half of the circumference of the esophagus and more than twothirds of its length ( $\nabla$ Fig. 2 a, b). One of these bullae had ruptured and was covered by a clot ( $\bullet$ Fig. 2c). The rubber bands were still in place. There was no ongoing bleeding. Within the next 18 hours, the hemoglobin concentration decreased to $7.6 \mathrm{~g} / \mathrm{dL}$, and the patient received two thrombocyte concentrates. At follow-up endoscopy after 6 weeks, the mucosa of the upper two-thirds of the esophagus was normal ( Fig.3). Varices were still present in the lowest third.

Intramural hematoma of the esophagus is a rare entity [1]. It may occur spontaneously; be secondary to a coagulopathy, as in myelofibrosis [2]; or develop after variceal sclerotherapy [3]. In our patient, low platelet counts, abnormal platelet function, sclerosis of the esophageal mucosa, and sclerotherapy may have been contributing factors. In summary, intramural hematoma of the esophagus is a rare complication that can result in severe blood loss. However, the prognosis is good with conservative management [4].

\section{Endoscopy_UCTN_Code_CCL_1AB_2AC_3AG}

\section{Competing interests: None}

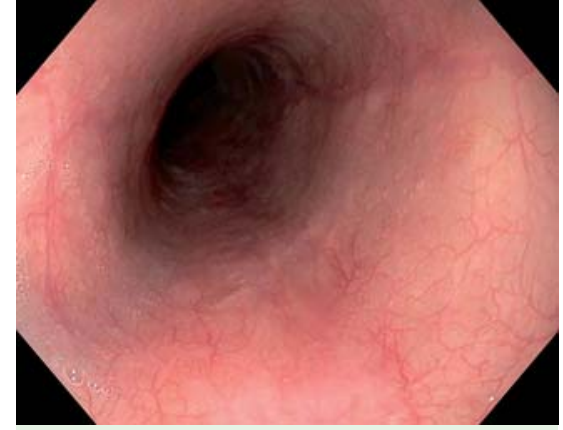

Fig. 3 Follow-up endoscopy after 6 weeks.

\section{Franziska Durchschein, \\ Elisabeth Krones, Andreas J. Eherer, Johannes Plank, Heinz F. Hammer}

Division of Gastroenterology and Hepatology, Department of Internal Medicine, Medical University of Graz, Austria

\section{References}

1 Jeong ES, Kim MJ, Yoo SH et al. Intramural hematoma of the esophagus after endoscopic pinch biopsy. Clin Endosc 2012; 45: 417-420

2 Tokai K, Miyatani H, Yoshida Yet al. Multiple esophageal variceal ruptures with massive ascites due to myelofibrosis-induced portal hypertension. World J Gastroenterol 2012; 18: $3770-3774$

3 Schmitz RJ, Sharma P, Badr AS et al. Incidence and management of esophageal stricture formation, ulcer bleeding, perforation, and
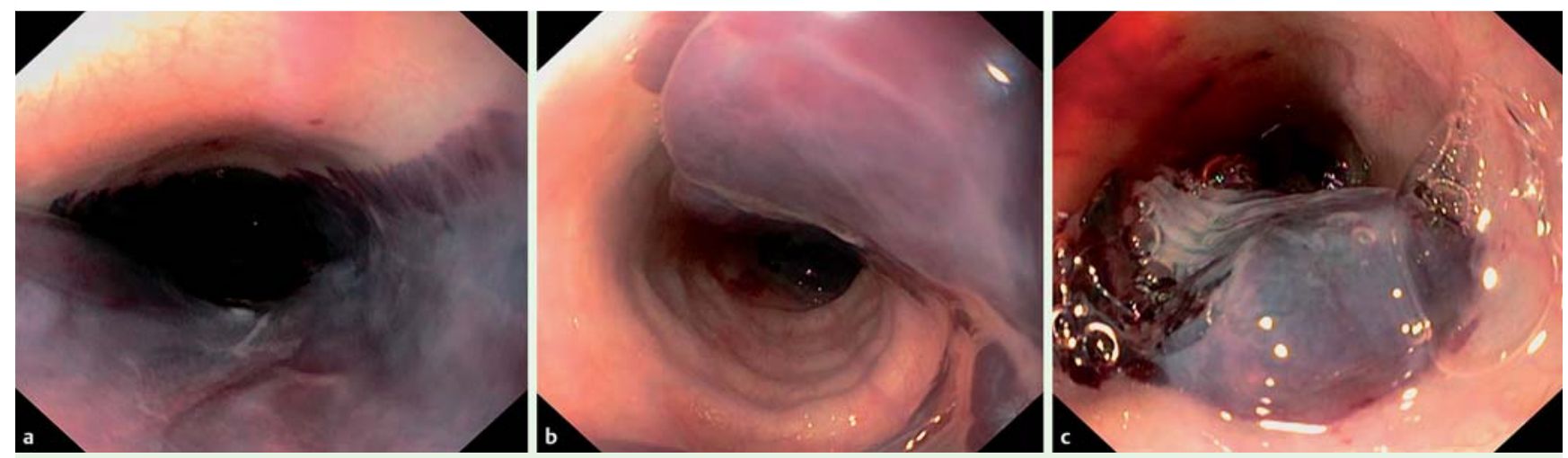

Fig. 2 a, b At second-look endoscopy, the bullous lesions have expanded. c A blood clot covers a ruptured bulla (to the left of the bulla). 
massive hematoma formation from sclerotherapy versus band ligation. Am J Gastroenterol 2001; 96: 437-441

4 Lukashok HP, Robles-Medranda C, de Santana $M A$ et al. Intramural esophageal hematoma after elective injection sclerotherapy. Arq Gastroenterol 2009; 46: 279-283
Bibliography

Dol http://dx.doi.org/

10.1055/s-0034-1390725

Endoscopy 2015; 47: E20-E21

(c) Georg Thieme Verlag KG

Stuttgart · New York

ISSN 0013-726X
Corresponding author

Heinz F. Hammer, MD

Division of Gastroenterology and Hepatology Department of Internal Medicine

Medical University of Graz

Auenbruggerplatz 15

8036 Graz

Austria

Fax: $+43(0) 316385-17108$

heinz.hammer@medunigraz.at 